\title{
A Study on a New Index of Vascular Stiffness: Gender Difference and Risk Factors
}

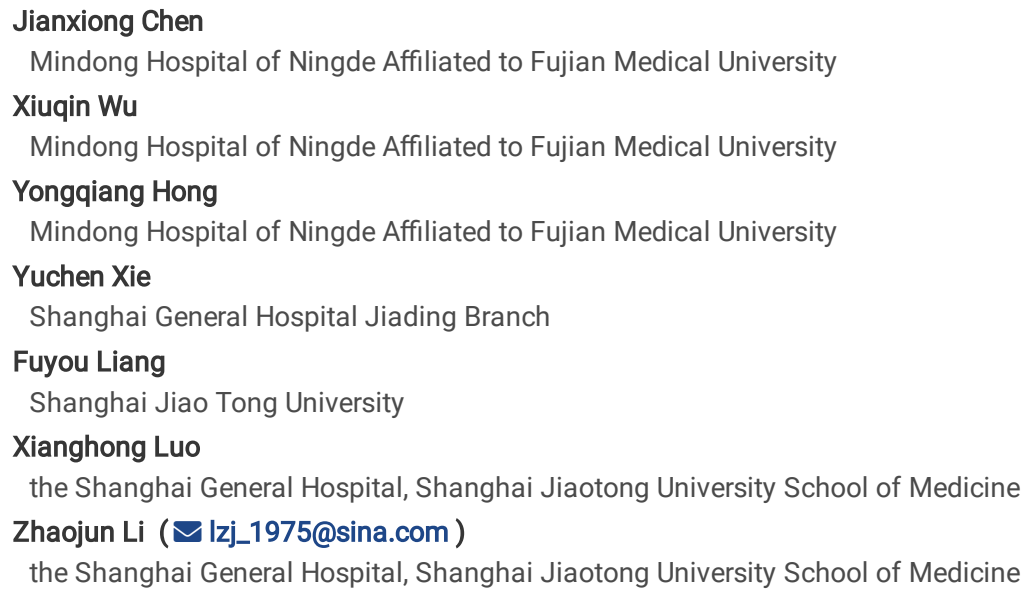




\section{Abstract}

Background: Previous studies have found that the gender differences have important influences on cardiovascular events, and arterial stiffness is an independent risk factor for cardiovascular events. The arterial pressure volume index (API) is a new indicator for the noninvasive assessment of muscular arterial stiffness. This study was aimed to preliminarily investigate on the gender differences and influencing factors of API from Chinese people, and to discuss the practical application implications of it.

Methods: A total of 11118 outpatients were randomly selected and divided into 5 groups according to the age from low to high quintile (Q1: < 37 years old group, Q2: $\geq 37$ years old group, Q3: $\geq 51$ years old group, Q4: $\geq 61$ years old group and Q5: $\geq 69$ years old group). The API was obtained by using the cuff oscillation wave for every subject. API $\geq 31$ was defined as high $\mathrm{API}$, and body mass index (BMI) $\geq 24 \mathrm{~kg} / \mathrm{m}^{2}$ was diagnosed as overweight. The differences of API and high API incidence between male and female subjects in the five groups were compared by Pearson correlation analysis. The risk factors of high API incidence were analyzed by multivariate logistic regression.

Results: $₫$ The differences in API and systolic blood pressure(SBP) between the 5 groups were statistically significant, and they increased with age (all $P<0.001)$. In the Q1 groups, the API of female was lower than that of male, while the API of female subjects was greater than that of male in the Q3 to Q5 group $(P<0.05)$. The incidence of high API was higher in male than in female $(P<0.05)$ in the Q1 group, but the incidence of high API was higher in female than in male $(P<0.05)$ in the Q3 to Q4 groups. खLogistic regression model indicated that the risk of high API for male subjects was 0.712 times that of female subjects $(95 \% \mathrm{Cl}: 0.584,0.840)(P<0.05)$. The risk of high API for overweight subjects was 1.327 times that of normal weight subjects $(95 \% \mathrm{Cl}$ : $1.236,1.418)$ $(P<0.05)$.

Conclusion: Among Chinese people of different ages, API differed between male and female; in the whole subjects, the risk of high API is higher for female subjects and overweight subjects.

\section{Background}

There are sex differences in the occurrence, development and outcome of cardiovascular disease (CVD), especially in terms of the time and degree of arterial stiffening[1]. Previous studies have shown that the degree of arteriosclerosis in women before menopause is lower than that in men, but it increases sharply after menopause and becomes indistinguishable from men's arteriosclerosis degree[2]. Increasing arterial stiffness is an independent risk factor for cardiovascular events and varies with gender and age[3]. The association between arterial stiffness and mortality in women was twofold higher than in men[4]. Previous studies have found the arterial stiffness of women is higher than that of men in low CVD risk individuals[5]. Therefore, understanding the difference of artery stiffness between men and women at different ages in the natural population is helpful for making clinical decisions.

The arterial pressure volume index (API) is a new oscillometric index of arterial stiffness. The measurement of API involves the use of a brachial cuff, which compresses the brachial artery with varying pressures (from a suprasystolic value to a value lower than diastolic pressure) to obtain a series of oscillation waves that are exploited to construct the transmural pressure-vascular volume curve of the brachial artery. The reciprocal of the maximum slope (which usually appears under low transmural pressure conditions) of the transmural pressure-vascular volume curve is termed as API, an index that is positively correlated with the mechanical property of arterial wall, and hence can be taken as an indicator of arterial stiffness [6]. Compared with conventional indices, the clinical measurement of API requires shorter time, has more comfortable postural requirements, and involves easier operation of device. These merits make the use of this measurement index suitable for broad clinical settings and screening of large communities. A large cross-sectional API research conducted in Japan found that API increases with age, Body mass index(BMI) and systolic blood pressure(SBP), and was associated with known risk factors of CVD(such as age, BMI, SBP, etc.), which suggests that API can be used to evaluate arterial elasticity and screen arteriosclerosis [7]. The study also found that the average API of women was higher than that of men; The API of hypertension, dyslipidemia and diabetes was higher than that of non-hypertensive patients[7]. How the API changes among Chinese people of different ages and different genders and what influencing factors are related to it have not been reported yet. We speculate that, among Chinese population, API increases with ages and differs between different ages and genders. This study aimed at the differences and related factors of the new arterial stiffness index API between different ages and genders in Chinese population.

\section{Materials And Methods}

\section{Subject}

The outpatients of Shanghai General Hospital Jiading Branch from august 2020 to June 2021 were selected. The inclusion criteria: $\otimes$ Complete API parameters; $\varangle$ No history of cardiovascular events and limb vessels diseases; $₫$ Patients who voluntarily participated in this research project were sane and able to understand and cooperate with the study. The exclusion criteria: $₫$ Clear diagnosis of cardiovascular events or limb vessels diseases; $\otimes$ Incomplete data of the cuff oscillation wave parameters. Figure 1 demonstrates the exclusion and inclusion criteria. This study protocol was approved by the medical ethics committee of Shanghai General Hospital (2019KY009-4) and registered on the official website of China Clinical Trial Registration Center (ChiCTR2000035937). Each participant has signed the informed consent form for this study.

\section{Instruments and methods}

General information

All subjects stopped taking antihypertensive drugs on the day of examination and were prohibited from smoking, alcohol drinking or coffee drinking for 24 hours. Each of them was asked to complete an electronic questionnaire to collect their general information such as height, body mass and body mass index. 
All the participants were asked to refrain from intensive physical activity in the 3 days prior to the study. Fasting blood samples were drawn after $8-12$ hours of fasting. Concentrations of total cholesterol (TC), triglycerides (TG), high-density lipoprotein (HDL) cholesterol, low-density lipoprotein (LDL) cholesterol, Fasting blood glucose(FBG), uric acid (UA), and Alanine aminotransferase (ALT) were assessed by standard reagent and automatic biochemical analyzer. The blood samples were centrifuged at 8000 RPM for 12 minutes and stored at $-80^{\circ} \mathrm{C}$ for further analysis.

API analysis

The room temperature was between 22 and $25^{\circ} \mathrm{C}$, and the subjects were asked to wear light clothes. They were then asked to sit and rest for 5 minutes. Portable arterial wave detector (PASESA AVE-2000Pro) was used to obtain brachial artery pressure volume index (API), SBP, diastolic blood pressure (DBP) and pulse data.

Repeatability test

Thirty randomly selected subjects' API were measured again by the same nurse one week later.

\section{Statistical methods}

SPSS23.0 software was used for statistical analysis. All p-values were two-sided, and a $P$-value of $<0.05$ was considered statistically significant. In the descriptive analysis, we presented as mean \pm SE for continuous variables. We further used single factor analysis of variance for evaluating difference among 5 groups and $\chi 2$ test for evaluating rate variables. The repeatability evaluation adopted a linear correlation analysis and Bland-Altman plots. Pearson correlation analysis was used for correlation analysis. API $\geq 31$ was defined as high API [8], BMI $\geq 24 \mathrm{~kg} / \mathrm{m} 2$ was diagnosed as overweight[9], and pulse $>80$ beats / min is defined as increased heart rate[10]. The API and BMI were converted into grade variables. Using SBP $\geq 140 \mathrm{mmHg}, \mathrm{DBP} \geq 90 \mathrm{mmHg}, \mathrm{ATL}>50$ $\mathrm{U} / \mathrm{L}, \mathrm{UA}>428.00 \mathrm{umol} / \mathrm{L}, \mathrm{TC} \geq 5.18 \mathrm{mmol} / \mathrm{L}, \mathrm{TG} \geq 1.70 \mathrm{mmol} / \mathrm{L}, \mathrm{HDL} \leq 1.04 \mathrm{mmol} / \mathrm{L}, \mathrm{LDL} \geq 2.58 \mathrm{mmol} / \mathrm{L}$ and $\mathrm{FBG}>6.10 \mathrm{mmol} / \mathrm{L}$ as the thresholds, the above independent variables were transformed into two categorical variables, and multivariate logistic regression analysis was performed to analyze the relative risk (OR) of high $\mathrm{API}$ of subjects such as gender and overweight. Statistical significance was considered to exist at $P<0.05$.

\section{Results}

\section{Comparison of general information}

A total of 11118 subjects aged from 11 to 98 years old participated in this study. It included 6767 females and 4351 males, with a mean age of $53.1 \pm 16.3$ years. They were divided into 5 groups according to age quintiles: 2301 cases in group Q1 (<37 years old), in which 1631 were female and 670 were male, with a mean age of $29.8 \pm 4.8 ; 2385$ cases in group Q2 ( $\geq 37$ years old), in which 1564 were female and 821 were male, with a mean age of $43.5 \pm 4.1 ; 2046$ cases in group Q3 ( $\geq 51$ years old), in which 1277 were female and 769 were male, with a mean age of $55.8 \pm 2.9 ; 2388$ cases in Q4 group ( $\geq 61$ years old), in which 1346 were female and 1042 were male, with a mean age of $64.6 \pm 2.2 ; 1998$ cases in Q5 group ( $\geq 69$ years old), in which 949 were female and 1049 were male, with a mean age of $74.9 \pm 5.6$. There were significant differences in gender ratio, age, height, body mass, body mass index, systolic blood pressure, diastolic blood pressure, pulse pressure, API, ALT, UA, TC, TG, HDL, LDL and FBG among the 5 groups (all $P<0.001)$. (Table 1,2)

Table 1

Baseline and clinical data of five groups by age quintile $(n=11118)$

\begin{tabular}{|c|c|c|c|c|c|c|c|c|c|}
\hline Item & $\begin{array}{l}\text { Gender } \\
\text { (female/male), } n / n\end{array}$ & $\begin{array}{l}\text { Age } \\
\text { (year), } \bar{x} \pm s\end{array}$ & $\begin{array}{l}\text { Height } / / \mathrm{cm} \text {, } \\
\overline{\mathbf{x} \pm s}\end{array}$ & $\begin{array}{l}\text { Body mass } \\
m / k g, \bar{x} \pm s\end{array}$ & $\begin{array}{l}\text { BMI } \\
\left(\mathrm{kg} / \mathrm{m}^{2}\right), \overline{\mathrm{x}} \\
\pm \mathrm{s}\end{array}$ & $\begin{array}{l}\text { SBP } \\
p / \\
\mathrm{mmHg}, \overline{\mathbf{x}} \pm \\
\mathrm{s}\end{array}$ & $\begin{array}{l}\text { DBP } \\
p / \\
\mathrm{mmHg}, \overline{\mathrm{x}} \pm \\
\mathrm{s}\end{array}$ & $\begin{array}{l}\text { Pulse } \\
\text { (times/min) } \bar{x} \\
\pm s\end{array}$ & $\begin{array}{l}\text { API } \\
\overline{\mathbf{x}} \pm s\end{array}$ \\
\hline Q1 & $1631 / 670$ & $\begin{array}{l}29.76 \pm \\
4.84\end{array}$ & $\begin{array}{l}165.02 \pm \\
7.79\end{array}$ & $62.28 \pm 13.71$ & $\begin{array}{l}22.73 \pm \\
3.90\end{array}$ & $\begin{array}{l}114.40 \pm \\
16.80\end{array}$ & $\begin{array}{l}74.02 \pm \\
11.41\end{array}$ & $85.37 \pm 13.93$ & $\begin{array}{l}25.14 \pm \\
5.24\end{array}$ \\
\hline Q2 & $1564 / 821$ & $\begin{array}{l}43.49 \pm \\
4.12\end{array}$ & $\begin{array}{l}163.84 \pm \\
7.46\end{array}$ & $65.43 \pm 12.58$ & $\begin{array}{l}24.26 \pm \\
3.68\end{array}$ & $\begin{array}{l}122.44 \pm \\
19.65\end{array}$ & $\begin{array}{l}79.20 \pm \\
13.74\end{array}$ & $80.70 \pm 12.07$ & $\begin{array}{l}25.60 \pm \\
5.59\end{array}$ \\
\hline Q3 & $1277 / 769$ & $\begin{array}{l}55.82 \pm \\
2.88\end{array}$ & $\begin{array}{l}163.07 \pm \\
7.27\end{array}$ & $65.04 \pm 10.90$ & $\begin{array}{l}24.39 \pm \\
3.29\end{array}$ & $\begin{array}{l}130.57 \pm \\
21.16\end{array}$ & $\begin{array}{l}80.81 \pm \\
12.92\end{array}$ & $79.04 \pm 12.40$ & $\begin{array}{l}27.93 \pm \\
6.33\end{array}$ \\
\hline Q4 & $1346 / 1042$ & $\begin{array}{l}64.65 \pm \\
2.19\end{array}$ & $\begin{array}{l}163.54 \pm \\
8.01\end{array}$ & $64.72 \pm 11.05$ & $\begin{array}{l}24.15 \pm \\
3.48\end{array}$ & $\begin{array}{l}135.44 \pm \\
22.29\end{array}$ & $\begin{array}{l}79.03 \pm \\
12.44\end{array}$ & $79.27 \pm 12.40$ & $\begin{array}{l}30.72 \pm \\
7.53\end{array}$ \\
\hline Q5 & $949 / 1049$ & $\begin{array}{l}74.90 \pm \\
5.62\end{array}$ & $\begin{array}{l}162.20 \pm \\
8.14\end{array}$ & $63.09 \pm 10.6$ & $\begin{array}{l}23.94 \pm \\
3.40\end{array}$ & $\begin{array}{l}141.41 \pm \\
24.59\end{array}$ & $\begin{array}{l}77.47 \pm \\
13.50\end{array}$ & $78.86 \pm 13.18$ & $\begin{array}{l}34.00 \pm \\
8.67\end{array}$ \\
\hline $\begin{array}{l}F / X^{2} \\
\text { value }\end{array}$ & 291.410 & 41163.330 & 38.753 & 29.310 & 80.745 & 570.648 & 89.898 & 102.727 & 653.894 \\
\hline $\begin{array}{l}P \\
\text { value }\end{array}$ & $<0.001$ & $<0.001$ & $<0.001$ & $<0.001$ & $<0.001$ & $<0.001$ & $<0.001$ & $<0.001$ & $<0.001$ \\
\hline \multicolumn{10}{|c|}{$1 \mathrm{mmHg}=0.133 \mathrm{kPa}$; BMI: Body mass index; SBP: Systolic blood pressure; DBP: Diastolic blood pressure; API: Arterial pressure volume index. } \\
\hline Q1:< & 2. & ears & $p, Q 3: \geq 51$ & s old group, Q & years old & oup and Q5 & 69 years & roup & \\
\hline
\end{tabular}


Table 2

Biochemical characteristics of five groups by age quintile $(\mathrm{n}=3693)$

\begin{tabular}{|c|c|c|c|c|c|c|c|c|}
\hline Item & $\begin{array}{l}\text { Gender } \\
\text { (female/male) } \\
n / n\end{array}$ & $\begin{array}{l}\text { ALT } \\
(U / L), \bar{x} \pm s\end{array}$ & $\begin{array}{l}\text { UA } \\
\text { (umol/L), } \bar{x} \pm \\
\text { s }\end{array}$ & $\begin{array}{l}\mathrm{TC} \\
(\mathrm{mmol} / \mathrm{L}), \overline{\mathrm{x}} \pm \\
\mathrm{s}\end{array}$ & $\begin{array}{l}\text { TG } \\
(\mathrm{mmol} / \mathrm{L}), \overline{\mathrm{x}} \pm\end{array}$ & $\begin{array}{l}\mathrm{HDL} \\
(\mathrm{mmol} / \mathrm{L}), \overline{\mathrm{x}} \pm \\
\mathrm{s}\end{array}$ & $\begin{array}{l}\text { LDL } \\
(\mathrm{mmol} / \mathrm{L}), \overline{\mathrm{x}} \pm \\
\mathrm{s}\end{array}$ & $\begin{array}{l}\text { FBG } \\
(\mathrm{mmol} / \mathrm{L}), \overline{\mathbf{x}} \pm \\
\mathrm{s}\end{array}$ \\
\hline Q1 & $169 / 118$ & $\begin{array}{l}33.12 \pm \\
83.26\end{array}$ & $\begin{array}{l}317.57 \pm \\
98.77\end{array}$ & $4.2 \pm 0.87$ & $1.21 \pm 0.71$ & $1.11 \pm 0.27$ & $2.71 \pm 0.87$ & $5 \pm 0.86$ \\
\hline Q2 & $370 / 291$ & $\begin{array}{l}29.99 \pm \\
26.89\end{array}$ & $\begin{array}{l}312.06 \pm \\
94.19\end{array}$ & $4.57 \pm 0.97$ & $1.59 \pm 1.29$ & $1.14 \pm 0.29$ & $2.92 \pm 0.94$ & $5.51 \pm 1.47$ \\
\hline Q3 & $448 / 334$ & $\begin{array}{l}29.41 \pm \\
22.71\end{array}$ & $\begin{array}{l}319.74 \pm \\
90.52\end{array}$ & $4.66 \pm 1.04$ & $1.6 \pm 1.19$ & $1.14 \pm 0.32$ & $2.95 \pm 0.94$ & $5.87 \pm 1.76$ \\
\hline Q4 & $536 / 522$ & $\begin{array}{l}27.15 \pm \\
21.13\end{array}$ & $\begin{array}{l}320.06 \pm \\
85.36\end{array}$ & $4.52 \pm 1.05$ & $1.45 \pm 0.9$ & $1.15 \pm 0.32$ & $2.83 \pm 0.99$ & $5.96 \pm 1.82$ \\
\hline Q5 & $401 / 504$ & $\begin{array}{l}23.99 \pm \\
16.58\end{array}$ & $\begin{array}{l}330.7 \pm \\
107.29\end{array}$ & $4.22 \pm 1.07$ & $1.35 \pm 0.76$ & $1.09 \pm 0.31$ & $2.59 \pm 0.97$ & $6.01 \pm 1.8$ \\
\hline $\mathrm{F} / \mathrm{X}^{2}$ value & 40.597 & 6.930 & 3.991 & 27.741 & 14.009 & 4.636 & 19.722 & 27.041 \\
\hline$P$ value & $<0.001$ & $<0.001$ & $<0.001$ & $<0.001$ & $<0.001$ & 0.001 & $<0.001$ & $<0.001$ \\
\hline
\end{tabular}

\section{Repeatability test}

The repeatability test showed the two measurements of API were highly correlated $(r=0.907, P<0.01)$, and the linear regression equation was $y=3.41+0.85 \chi$. Bland-Altman analysis showed that the mean and standard deviation of the difference between the two API measurements were (-0.96 \pm 2.41$)$, and the two measurements showed a consistent trend between the differential value and the mean value(Fig. 2).

\section{Intra-group differences of BMI, SBP, DBP, and API between male and female}

In groups Q1, Q2 and Q3, the BMI values in female were all found to be lower than that in male, and they all had statistical differences (all $P<0.05)$. However, in Q5 group, the BMI was higher in female than in male $(P<0.05)$. In groups Q1 to Q4, the SBP was higher in male than in female (all $P<0.05)$, while in Q5 group, the SBP was higher in female than in male $(P<0.05)$. In all five groups, male has higher DBP than female (all $P<0.05)$. In Q1, Q3, Q4 and Q5, API had intra-group difference between male and female. API of male was higher than that of female in Q1, while API of male was lower than that of female in Q3 to Q5 (all $P<0.05$ ). To clarify the incidence of high API in male and in female subjects, API $\geq 31$ was defined as a high API. It was found that in the Q1 group, the probability of high API was higher in male than in female $(P<0.05)$; while in Q3 to Q4 groups, the probability of high API was higher in female than in male $(P$ $<0.05)$. See Table 3. 
Comparison of different genders of subjects grouped by age quintile $(n=11118)$

\begin{tabular}{|c|c|c|c|c|c|c|}
\hline \multirow[t]{2}{*}{ Item } & & BMI & SBP & DBP & API & High API \\
\hline & & $\left(\mathrm{kg} / \mathrm{m}^{2}\right), \overline{\mathrm{x}} \pm \mathrm{s}$ & $p / \mathrm{mmHg}, \overline{\mathrm{x}} \pm \mathrm{s}$ & $p / m m H g, \bar{x} \pm s$ & $\overline{\mathbf{x}} \pm s$ & $n / n$ \\
\hline \multirow[t]{3}{*}{ Q1 (1631/670) } & Female & $21.94 \pm 3.43$ & $110.21 \pm 14.33$ & $71.25 \pm 9.87$ & $24.46 \pm 5.00$ & $165 / 1466$ \\
\hline & Male & $24.65 \pm 4.29$ & $124.59 \pm 17.97$ & $80.75 \pm 12.08$ & $26.81 \pm 5.43$ & $137 / 533$ \\
\hline & $P$ value & $<0.001^{a}$ & $<0.001^{\mathrm{a}}$ & $<0.001^{a}$ & $<0.001^{a}$ & $<0.001^{b}$ \\
\hline \multirow[t]{3}{*}{ Q2 (1564/821) } & Female & $23.6 \pm 3.69$ & $118.83 \pm 18.2$ & $75.37 \pm 11.86$ & $25.52 \pm 5.52$ & $255 / 1309$ \\
\hline & Male & $25.51 \pm 3.31$ & $129.31 \pm 20.49$ & $86.48 \pm 14.15$ & $25.74 \pm 5.73$ & $128 / 693$ \\
\hline & $P$ value & $<0.001^{a}$ & $<0.001^{a}$ & $<0.001^{a}$ & $0.372^{a}$ & $0.681^{b}$ \\
\hline \multirow[t]{3}{*}{ Q3 (1277/769) } & Female & $24.09 \pm 3.37$ & $128.16 \pm 19.68$ & $77.76 \pm 11.81$ & $28.29 \pm 6.36$ & $404 / 873$ \\
\hline & Male & $24.9 \pm 3.09$ & $134.56 \pm 22.87$ & $85.87 \pm 13.11$ & $27.33 \pm 6.23$ & $199 / 570$ \\
\hline & $P$ value & $<0.001^{a}$ & $<0.001^{a}$ & $<0.001^{a}$ & $0.001^{a}$ & $0.005^{b}$ \\
\hline \multirow[t]{3}{*}{ Q4 (1346/1042) } & Female & $24.07 \pm 3.68$ & $134.12 \pm 21.99$ & $76.84 \pm 11.98$ & $31.3 \pm 7.77$ & $687 / 659$ \\
\hline & Male & $24.26 \pm 3.22$ & $137.14 \pm 22.58$ & $81.86 \pm 12.45$ & $29.97 \pm 7.13$ & $433 / 609$ \\
\hline & $P$ value & $0.182^{a}$ & $0.001^{a}$ & $<0.001^{a}$ & $<0.001^{a}$ & $<0.001^{b}$ \\
\hline \multirow[t]{3}{*}{ Q5 (949/1049) } & Female & $24.07 \pm 3.6$ & $142.87 \pm 24.76$ & $76.24 \pm 13.77$ & $35.63 \pm 8.75$ & $661 / 288$ \\
\hline & Male & $23.83 \pm 3.21$ & $140.09 \pm 24.37$ & $78.58 \pm 13.17$ & $32.52 \pm 8.32$ & $560 / 489$ \\
\hline & $P$ value & $0.114^{a}$ & $0.012^{a}$ & $<0.001^{a}$ & $<0.001^{a}$ & $<0.001^{b}$ \\
\hline $\begin{array}{l}1 \mathrm{mmHg}=0.133 \\
\text { years old group, } \\
\text { a Student's t test. }\end{array}$ & \multicolumn{5}{|c|}{$\begin{array}{l}1 \mathrm{mmHg}=0.133 \mathrm{kPa} \text {; BMl: Body mass index; } \mathrm{SBP} \text { : Systolic blood pressure; DBP: Diastolic blood pressure; API: Arterial pressure volume index. Q1: < } 37 \\
\text { years old group, Q2: } \geq 37 \text { years old group, Q3: } \geq 51 \text { years old group, Q4: } \geq 61 \text { years old group and Q5: } \geq 69 \text { years old group. }\end{array}$} & ex. Q1: < 37 \\
\hline
\end{tabular}

\section{Multiple logistic regression analysis in high API}

The simple correlation analysis suggested that API was positively correlated with age, weight, BMI, SBP, DBP, UA, TG and FBG $(r=0.425,0.116,0.199,0.683$, $0.071,0.088,0.044$ and 0.124 , all $P<0.01)$, and negatively correlated with height, pulse, ALT and LDL $(r=-0.092,-0.098,-0.039$ and -0.038 , all $P<0.01)$.

(Fig. 2.)

To further clarify the relationship between high API and gender, as well as overweight and other influencing factors, logistic regression model was used to analyze the independent influencing factors of high API. The results revealed that gender, BMI, SBP, DPB, pulse, ALT, UA, TC, TG, HDL, LDL and FBG were all independent influencing factors for high API. The risk of high API of male was 0.712 times that of female in all objects $(95 \% \mathrm{Cl}$ : $0.584,0.840)(P<0.01)$. The risk of high API in the higher age group subjects was 1.575 times higher than that in the lower age group subjects $(95 \% \mathrm{Cl}$ : 1.535, 1.616) $(P<0.01)$. The risk of high API in overweight subjects was 1.327 times than that of normal weight subjects $(95 \% \mathrm{Cl}: 1.236,1.418)(P<0.01)$. The risk of high API was 19.424 times higher in those with high SBP than in those with normal SBP $(95 \% \mathrm{Cl}: 19.312,19.537)(P<0.01)$. The risk of high API was 1.465 times higher in those with elevated FBG than in those with normal FBG $(95 \% \mathrm{Cl}$ : $1.365,1.565)(p<0.01)$. In the female group, the OR $(95 \% \mathrm{Cl})$ for high API in overweight objects $=1.344$ $(1.216,1.472)(P<0.05)$ and the risks of high API in high SBP and elevated FBP were 23.551 times and 1.539 times higher than that in normal subjects, respectively (all $P<0.01)$. In the male group, the OR $(95 \% \mathrm{Cl})$ for high API in overweight object $=1.277(1.146,1.409)(P>0.05)$ and the risks of high API in patients with high SBP and elevated FBP were 16.765 times and 1.371 times higher than that in normal subjects, respectively $(P<0.05)$. (Table 4 and Fig. 4 .). 
Table 4

Multivariate logistic regression model analysis of risk factors for increased API $(n=3693)$

\begin{tabular}{|c|c|c|c|c|c|c|c|c|c|c|c|}
\hline \multirow[t]{2}{*}{ Item } & \multicolumn{4}{|l|}{ All participants } & \multicolumn{4}{|l|}{ Female } & \multicolumn{3}{|l|}{ Male } \\
\hline & $\begin{array}{l}\text { Standardized } \\
\text { regression } \\
\text { coefficient }\end{array}$ & $\begin{array}{l}P \\
\text { value }\end{array}$ & OR & $95 \% \mathrm{Cl}$ & $\begin{array}{l}\text { Standardized } \\
\text { regression } \\
\text { coefficient }\end{array}$ & $\begin{array}{l}P \\
\text { value }\end{array}$ & OR & $95 \% \mathrm{Cl}$ & $\begin{array}{l}\text { Standardized } \\
\text { regression } \\
\text { coefficient }\end{array}$ & $\begin{array}{l}P \\
\text { value }\end{array}$ & OR \\
\hline Gender & -0.340 & 0.008 & 0.712 & $0.584,0.840$ & & & & & & & \\
\hline Age group & 0.455 & $\begin{array}{l}< \\
0.001\end{array}$ & 1.575 & $1.535,1.616$ & 0.544 & $\begin{array}{l}< \\
0.001\end{array}$ & 1.724 & $1.667,1.780$ & 0.357 & $\begin{array}{l}< \\
0.001\end{array}$ & 1.430 \\
\hline Overweight & 0.283 & 0.002 & 1.327 & $1.236,1.418$ & 0.295 & 0.021 & 1.344 & $1.216,1.472$ & 0.245 & 0.062 & 1.277 \\
\hline Height & -0.024 & 0.002 & 0.976 & $0.969,0.984$ & -0.031 & 0.007 & 0.969 & $0.958,0.981$ & -0.018 & 0.087 & 0.983 \\
\hline $\begin{array}{l}\mathrm{SBP} \geq 140 \\
\mathrm{mmHg}\end{array}$ & 2.967 & $<.001$ & 19.424 & $19.312,19.537$ & 3.159 & $\begin{array}{l}< \\
0.001\end{array}$ & 23.551 & $23.379,23.724$ & 2.819 & $\begin{array}{l}< \\
0.001\end{array}$ & 16.765 \\
\hline $\begin{array}{l}\mathrm{DBP} \geq 90 \\
\mathrm{mmHg}\end{array}$ & -1.021 & $\begin{array}{l}< \\
0.001\end{array}$ & 0.360 & $0.233,0.488$ & -1.286 & $\begin{array}{l}< \\
0.001\end{array}$ & 0.276 & $0.070,0.483$ & -0.890 & $\begin{array}{l}< \\
0.001\end{array}$ & 0.410 \\
\hline $\begin{array}{l}\text { Pulse }>80 \\
\text { times/min }\end{array}$ & -0.433 & $\begin{array}{l}< \\
0.001\end{array}$ & 0.649 & $0.560,0.738$ & -0.548 & $<.001$ & 0.578 & $0.450,0.707$ & -0.308 & 0.014 & 0.735 \\
\hline $\begin{array}{l}\text { ALT > } \\
50.00 \mathrm{U} / \mathrm{L}\end{array}$ & 0.106 & 0.495 & 1.112 & $0.957,1.268$ & 0.312 & 0.204 & 1.366 & $1.121,1.611$ & -0.094 & 0.640 & 0.910 \\
\hline $\begin{array}{l}\text { UA > } \\
428.00 \\
\text { umol/L }\end{array}$ & 0.177 & 0.179 & 1.194 & $1.062,1.325$ & 0.193 & 0.439 & 1.213 & $0.963,1.463$ & 0.146 & 0.341 & 1.158 \\
\hline $\begin{array}{l}\mathrm{TC} \geq 5.18 \\
\mathrm{mmol} / \mathrm{L}\end{array}$ & -0.125 & 0.296 & 0.883 & $0.763,1.002$ & -0.108 & 0.507 & 0.898 & $0.735,1.060$ & -0.142 & 0.432 & 0.868 \\
\hline $\begin{array}{l}\mathrm{TG} \geq 1.70 \\
\mathrm{mmol} / \mathrm{L}\end{array}$ & 0.185 & 0.078 & 1.203 & $1.098,1.308$ & 0.124 & 0.417 & 1.132 & $0.979,1.285$ & 0.200 & 0.171 & 1.222 \\
\hline $\begin{array}{l}\mathrm{HDL} \leq \\
1.04 \\
\mathrm{mmol} / \mathrm{L}\end{array}$ & 0.114 & 0.242 & 1.121 & $1.023,1.218$ & 0.141 & 0.322 & 1.152 & $1.009,1.294$ & 0.075 & 0.574 & 1.078 \\
\hline $\begin{array}{l}\mathrm{LDL} \geq 2.58 \\
\mathrm{mmol} / \mathrm{L}\end{array}$ & -0.147 & 0.133 & 0.863 & $0.765,0.961$ & -0.237 & 0.103 & 0.789 & $0.644,0.934$ & -0.068 & 0.611 & 0.934 \\
\hline $\begin{array}{l}\mathrm{FBG}>6.10 \\
\mathrm{mmol} / \mathrm{L}\end{array}$ & 0.382 & $<.001$ & 1.465 & $1.365,1.565$ & 0.431 & 0.004 & 1.539 & $1.387,1.690$ & 0.316 & 0.019 & 1.371 \\
\hline
\end{tabular}

BMI: Body mass index; SBP: Systolic blood pressure; DBP: Diastolic blood pressure; API: Arterial pressure volume index; ALT: Alanine aminotransferase; UA: U Cholesterol; TG: Triglycerides; HDL: High-density lipoprotein; LDL: low-density lipoprotein; FBG: Fasting blood glucose;

\section{Discussion}

This study obtained a new index of vascular stiffness, API, in a large sample of Chinese population. The results showed that API increased with age in Chinese population, and high API was associated with common vascular risk factors such as age, weight, systolic blood pressure, uric acid, triglyceride, and fasting blood glucose. There were differences in API between male and female subjects in some age groups of the Chinese population.

For subjects older than 51 years, the females were more likely to have higher API, while for subjects younger than 37 years female tended to have lower API. In the studied Chinese population, women, overweight people and high SBP people had higher risks of high.

The progression of arteriosclerosis is different in male and female[11]. API is a new index to reflect the residual stress/strain for the brachial artery wall with zero transmural pressure, and it can be used to assess vascular stiffness and monitor arterial aging and remodeling[7, 12]. Narkiewicz et al. proposed gender aging curves and found differences in vascular aging curves between males and females, in which male showed a linear upward trend in vascular stiffness while female showed a curvilinear aging trend. They also found that younger women have flatter curves and older women have rapidly rising curves[13]. This study revealed that there were differences in sexual API between men and women of different ages, which was similar to the results of Narkiewicz et al. Epidemiological studies found that vascular stiffness was higher in men than in women before the age of 58 years, and the increasing rate in vascular stiffness was higher in women than in men after menopause[14]. In this study, API was found to be higher in younger men than in younger women, while it was higher in women older than 51 years conversely. This difference could be explained by the fact that postmenopausal women have a higher susceptibility to arterial stiffness due to a significant decrease in estrogen levels along with oxidative stress and iron accumulation in the body as ovarian function gradually decreases[14, 15]. Estrogen can affect arterial wall stiffness by modulating the collagen/elastin fiber ratio and matrix metalloproteinase activity[16]. In addition, estrogen could regulate lipid metabolism and protect vascular endothelial function. The decrease of the estrogen levels in postmenopausal women leads to disturbances in lipid metabolism and impaired vascular endothelial function, which accelerates atherosclerosis[17].

Overweight is an independent risk factor for hypertension and atherosclerosis, especially for women[18]. This study found that increased API was positively associated with overweight and systolic blood pressure. In this study, the risk of high API in overweight individuals was 1.327 times higher than that in normal weight individuals, and the risk in overweight women was 1.344 times higher than in normal weight women. Mizia-Stec K et al. [19] compared the indices of 
arterial structure and function in women with and without simple obesity and found that simple obesity was an important risk factor for accelerating arterial stiffness in women, which is consistent with the results of this study. This may be related to the overweight individuals' adipose tissue secretion or overexpression of cell active factors, such as interleukin- 6 and tumor necrosis factor-a, which mediate the secretion of vascular endothelial cells. Also, the imbalance of coagulation and fibrinolysis results in abnormal systolic and diastolic function of blood vessels, which further leads to impaired endothelial function and induces atherosclerosis[1, 20].

This study found that systolic blood pressure was an independent influencing factor for API. The risk of high API in patients with increased SBP was 19.424 times higher than that in patients with normal blood pressure, which was consistent with previous studies and suggested that the new index API can be used to assess atherosclerosis. Elevated blood pressure, especially SBP, increases the pressure of the aortic wall when the blood is pulsating, which can lead to elastin degradation, collagen matrix deposition, vascular calcification, endothelial dysfunction, and eventually arteriosclerosis [21]. In recent years, some scholars proposed the causal relationship between arteriosclerosis and hypertension, in which they claimed there was an insidious positive feedback loop between local mechanical and biological responses and global hemodynamic results[22, 23]. Interestingly, this study found that the increase of DBP is a " protective factor " for the occurrence of high API. Previous studies have also reported that there was a negative correlation between arterial stiffness indices PWV[24], but the exact mechanism remains to be further elucidated.

Hyperglycemia is a risk factor for arteriosclerosis[25]. This study found that FBG was positively correlated with API, and was an independent risk factor for high API. Kim M, et al[26] found that FBG was positively correlated with arterial stiffness. Wang j et al. [27] randomly selected 5039 subjects over the age of 40 (40.0\% women) and used pulse wave velocity (PWV) as an index to evaluate arterial stiffness. The result found that the risk of arterial stiffness in participant with impaired FBG was 1.82 times higher than those with normal FBG. This result is consistent with the findings of this study, where the risk of high API in subjects with impaired FBG was 1.465 times higher than those with normal FBG. The increase of arterial stiffness caused by elevated blood was probably because high blood glucose could induce endothelial cell apoptosis, increase the expression of intercellular adhesion molecule E and interleukin-6[28], strengthen the polyether polyol, protein kinase-C and the pentose phosphate pathway, accelerate vascular endothelial cell apoptosis, and induce vascular endothelial dysfunction[29]. Additionally, high-level FBG could cause more insulin resistant, induce the proliferation and migration of vascular smooth muscle cells, and accelerate arterial stiffness[30].

It is worth mentioned that this study also found that height was negatively correlated with API, and was an independent influencing factor for API, with the height higher, the API lower. This result has not been reported before. We speculated this may be API is an indicator of residual stress in the vasculature. In natural conditions, the distribution of residual stress in the arterial tree is characterized by a greater proximal than distal end, with inner layer compressed and outer layer extended. The compression degree of the inner layer along the arterial tree has no significant change, while the extension degree of the outer layer decreases from the proximal to the distal end [15]. Therefore, the API is lower for tall people. On the other hand, API may reflect the stiffness of muscular arteries and is more susceptible to the response degree of cellular mechanoreceptors. The fact that both blood pressure and pulse are based on cellular mechanoreceptors causes the changes in vascular structure and function, which lead to changes in vascular viscoelasticity and residual stress [31, 32]. This is consistent with the findings of our study that blood pressure and pulse affect API independently.

There are some limitations in the study. This was a single center cross-sectional and retrospective study, which didn't fully represent the characteristics of Chinese population. The subjects were outpatients, whose API did not fully reflect the distribution characteristics of API in the natural population. However, since everyone might be sick and need to go to the hospital and our sample data were collected from the outpatients, the results of this study is still plausible. Another thing to point out is that the BMI parameters did not consider the influence of fat distribution and visceral fat status on API. In future studies, we expect to confirm what could be identified as high API outcome events.

\section{Conclusions}

The cuff oscillation wave was used to obtain a new index API that can reflect the arteries stiffness, and this conclusion was verified by a large Chinese population sample. In this study, the results showed API increased with age, and the increase was associated with common vascular risk factors, in which SBP, DBP, pulse and FBG were the independent influencing factors. These results suggest that API can be used as an alternative index for vascular stiffness screening. In some age groups of Chinese population, API differed between men and women, and the risk of high API is higher in women. This result suggests that we should pay more attention to the differences in vascular stiffness between genders in some specific age groups, which should be treated differently in clinical practice.

\section{Abbreviations}

API: The arterial pressure volume index; SBP: Systolic blood pressure; CVD: Cardiovascular disease; BMI: Body mass index; TC: Concentrations of total cholesterol; TG: Triglycerides; HDL: High-density lipoprotein cholesterol; LDL: Low-density lipoprotein cholesterol; FBG: Fasting blood glucose; UA: Uric acid; ALT: Alanine aminotransferase; DBP: Diastolic blood pressure; OR: The relative risk; PWV: Pulse wave velocity

\section{Declarations}

\section{Acknowledgements}

Not applicable.

\section{Funding}


This study was sponsored by Natural Science Foundation of Shanghai (21ZR1451400) and Shanghai Songjiang District Science and Technology Project (18sjkjgg72,18sjkjgg53). There are no relationships with the company relating to employment, consultancy, patents, products in development or marketed products.

\section{Availability of data and materials}

The data supporting the findings of this study are available from the corresponding author upon reasonable request.

\section{Ethics approval and consent to participate}

This study protocol was approved by the medical ethics committee of Shanghai General Hospital (2019KY009-4) and registered on the official website of China Clinical Trial Registration Center (ChiCTR2000035937). All subjects gave written informed consent in accordance with the Declaration of Helsinki. Children and adolescents under age of 16 signed an assent form, and got their parents's written consents to be included in the study.

\section{Competing interests}

The authors declare that they have no competing interests.

\section{Consent for publication}

Not applicable.

\section{Authors' contributions}

Jianxiong Chen: study design and concept, data acquisition, data analysis and interpretation, and preparation of the first and subsequent manuscript drafts; Xiuqin Wu: study design and concept, data acquisition, and manuscript preparation and review; Yongqiang Hong: study design and concept, and manuscript review and editing; Yuchen Xie: data acquisition and manuscript review; Fuyou Liang: study design and concept, manuscript review and approving the final version; Xianghong Luo: study design and concept, data analysis and interpretation, and manuscript review; Zhaojun Li: study design and concept, manuscript review and editing, and approving the final version.

\section{References}

1. DuPont JJ, Kenney RM, Patel AR, Jaffe IZ: Sex differences in mechanisms of arterial stiffness. Br J Pharmacol 2019, 176(21):4208-25.

2. Hildreth KL, Kohrt WM, Moreau KL: Oxidative stress contributes to large elastic arterial stiffening across the stages of the menopausal transition. Menopause 2014, 21(6):624-32.

3. Mathur P, Ostadal B, Romeo F, Mehta JL: Gender-Related Differences in Atherosclerosis. Cardiovascular drugs and therapy 2015, $29(4): 319-27$.

4. Regnault V, Thomas F, Safar ME, Osborne-Pellegrin M, Khalil RA, Pannier B et al: Sex difference in cardiovascular risk: role of pulse pressure amplification. J Am Coll Cardiol 2012, 59(20):1771-7.

5. Wang Z, Li W, Liu W, Tian J: Gender is a determinant of carotid artery stiffness independent of age and blood pressure. Br J Radiol 2021, 94(1119):20200796.

6. Zhang X, Gou Z, Wang T, Liang F: Application of biomechanical modeling and simulation in the development of non-invasive technologies and devices for cardiovascular testing. Sheng Wu Yi Xue Gong Cheng Xue Za Zhi 2020, 37(6):990-9.

7. Okamoto M, Nakamura F, Musha T, Kobayashi Y: Association between novel arterial stiffness indices and risk factors of cardiovascular disease. BMC cardiovascular disorders 2016, 16(1):211.

8. Yamanashi H, Koyamatsu J, Nagayoshi M, Shimizu Y, Kawashiri SY, Kondo H et al: Screening Validity of Arterial Pressure-Volume Index and Arterial Velocity-Pulse Index for Preclinical Atherosclerosis in Japanese Community-Dwelling Adults: the Nagasaki Islands Study. J Atheroscler Thromb 2018, 25(9):792-8.

9. Tang B, Luo F, Zhao J, Ma J, Tan I, Butlin M et al: Relationship between body mass index and arterial stiffness in a health assessment Chinese population. Medicine 2020, 99(3):e18793.

10. Palatini P, Rosei EA, Casiglia E, Chalmers J, Ferrari R, Grassi G et al: Management of the hypertensive patient with elevated heart rate: Statement of the Second Consensus Conference endorsed by the European Society of Hypertension. J Hypertens 2016, 34(5):813-21.

11. Safar ME, Regnault V, Lacolley P: Sex Differences in Arterial Stiffening and Central Pulse Pressure: Mechanistic Insights? J Am Coll Cardiol 2020, 75(8):881-3.

12. Komine H, Asai Y, Yokoi T, Yoshizawa M: Non-invasive assessment of arterial stiffness using oscillometric blood pressure measurement. Biomed Eng Online 2012, 11:6.

13. Narkiewicz K, Kjeldsen SE, Hedner T: Hypertension and cardiovascular disease in women: progress towards better understanding of gender-specific differences? Blood pressure 2006, 15(2):68-70.

14. Lu Y, Pechlaner R, Cai J, Yuan H, Huang Z, Yang G et al: Trajectories of Age-Related Arterial Stiffness in Chinese Men and Women. J Am Coll Cardiol 2020, 75(8):870-80.

15. Sokolis DP: Time-course of axial residual strain remodeling and layer-specific thickening during aging along the human aorta. J Biomech 2020, 112:110065. 
16. Liu SL, Bajpai A, Hawthorne EA, Bae Y, Castagnino P, Monslow J et al: Cardiovascular protection in females linked to estrogen-dependent inhibition of arterial stiffening and macrophage MMP12. JCl insight 2019, 4(1).

17. Ogola BO, Zimmerman MA, Clark GL, Abshire CM, Gentry KM, Miller KS et al: New insights into arterial stiffening: does sex matter? Am J Physiol Heart Circ Physiol 2018, 315(5):H1073-h87.

18. Scuteri A, Orru M, Morrell CH, Tarasov K, Schlessinger D, Uda M et al: Associations of large artery structure and function with adiposity: effects of age, gender, and hypertension. The SardiNIA Study. Atherosclerosis 2012, 221(1):189-97.

19. Mizia-Stec K, Gasior Z, Zahorska-Markiewicz B, Holecki M, Haberka M, Mizia M et al: The indexes of arterial structure and function in women with simple obesity: a preliminary study. Heart Vessels 2008, 23(4):224-9.

20. Campia U, Tesauro M, Cardillo C: Human obesity and endothelium-dependent responsiveness. Br J Pharmacol 2012, 165(3):561-73.

21. Humphrey JD, Harrison DG, Figueroa CA, Lacolley P, Laurent S: Central Artery Stiffness in Hypertension and Aging: A Problem With Cause and Consequence. Circ Res 2016, 118(3):379-81.

22. Safar ME, Asmar R, Benetos A, Blacher J, Boutouyrie P, Lacolley P et al: Interaction Between Hypertension and Arterial Stiffness. Hypertension 2018, 72(4):796-805.

23. Laurent S, Boutouyrie P: The structural factor of hypertension: large and small artery alterations. Circ Res 2015, 116(6):1007-21.

24. Georgianos PI, Agarwal R: Aortic Stiffness, Ambulatory Blood Pressure, and Predictors of Response to Antihypertensive Therapy in Hemodialysis. Am J Kidney Dis 2015, 66(2):305-12.

25. Katakami N: Mechanism of Development of Atherosclerosis and Cardiovascular Disease in Diabetes Mellitus. J Atheroscler Thromb 2018, 25(1):27-39.

26. Kim M, Yoo HJ, Kim M, Seo H, Chae JS, Lee SH et al: Influence of estrogen-related receptor Y (ESRRG) rs1890552 A> G polymorphism on changes in fasting glucose and arterial stiffness. Sci Rep 2017, 7(1):9787.

27. Wang J, Liu L, Zhou Y, Wang C, Hu H, Hoff K et al: Increased fasting glucose and the prevalence of arterial stiffness: a cross-sectional study in Chinese adults. Neurological research 2014, 36(5):427-33.

28. Ohnishi H, Saitoh S, Takagi S, Ohata J, Isobe T, Kikuchi Y et al: Pulse wave velocity as an indicator of atherosclerosis in impaired fasting glucose: the Tanno and Sobetsu study. Diabetes Care 2003, 26(2):437-40.

29. van Popele NM, Elizabeth Hak A, Mattace-Raso FU, Bots ML, van der Kuip DA, Reneman RS et al: Impaired fasting glucose is associated with increased arterial stiffness in elderly people without diabetes mellitus: the Rotterdam Study. J Am Geriatr Soc 2006, 54(3):397-404.

30. Xu L, Jiang CQ, Lam TH, Cheng KK, Yue XJ, Lin JM et al: Impact of impaired fasting glucose and impaired glucose tolerance on arterial stiffness in an older Chinese population: the Guangzhou Biobank Cohort Study-CVD. Metabolism: clinical and experimental 2010, 59(3):367-72.

31. Xiao H, Tan I, Butlin M, Li D, Avolio AP: Arterial viscoelasticity: role in the dependency of pulse wave velocity on heart rate in conduit arteries. Am J Physiol Heart Circ Physiol 2017, 312(6):H1185-h94.

32. Luo X, Du L, Li Z: Ultrasound assessment of tensile stress in carotid arteries of healthy human subjects with varying age. BMC medical imaging 2019, 19(1):93.

\section{Figures}




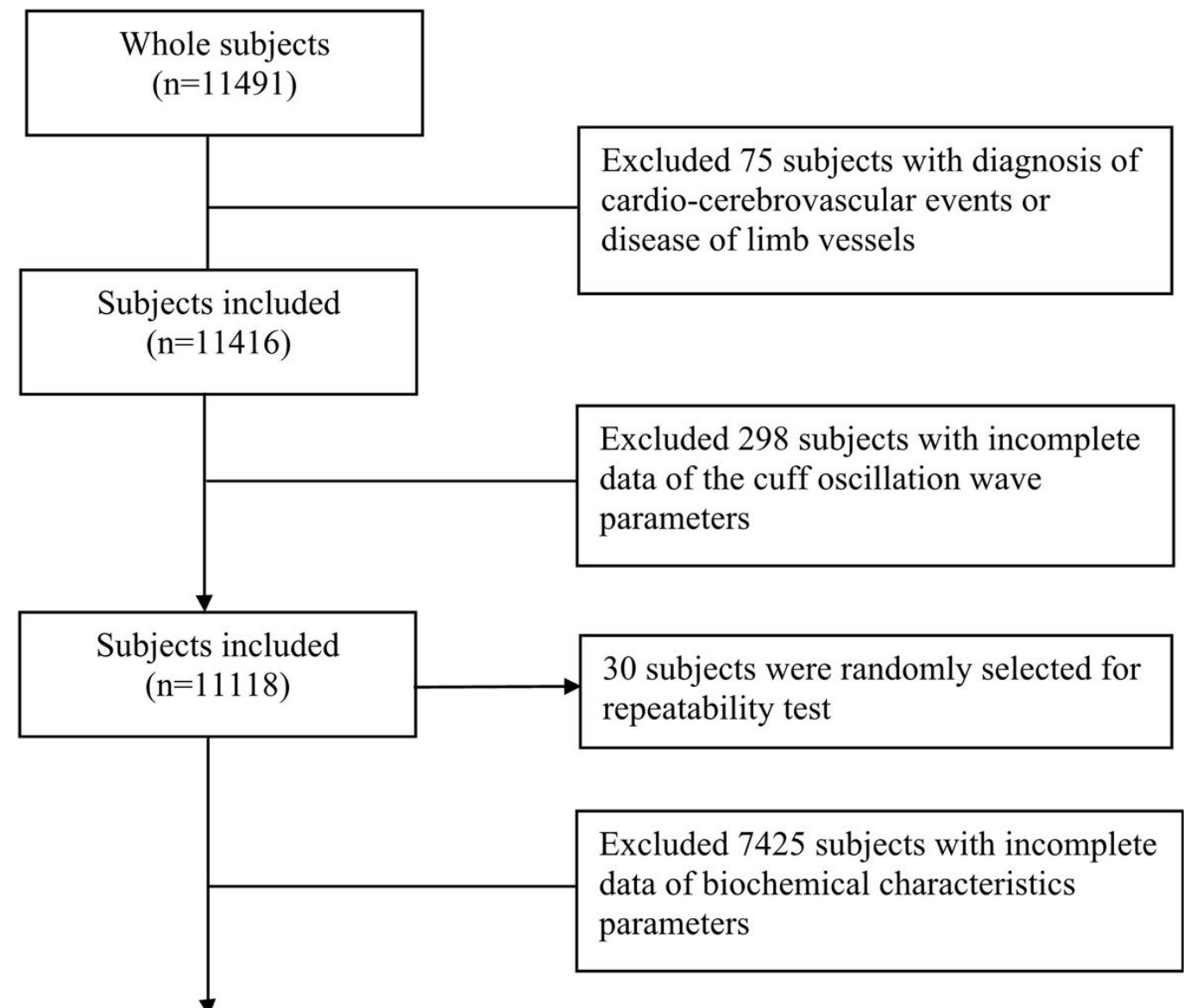

Subjects included $(n=3693)$

Figure 1

Flowchart of patients' selection in this study
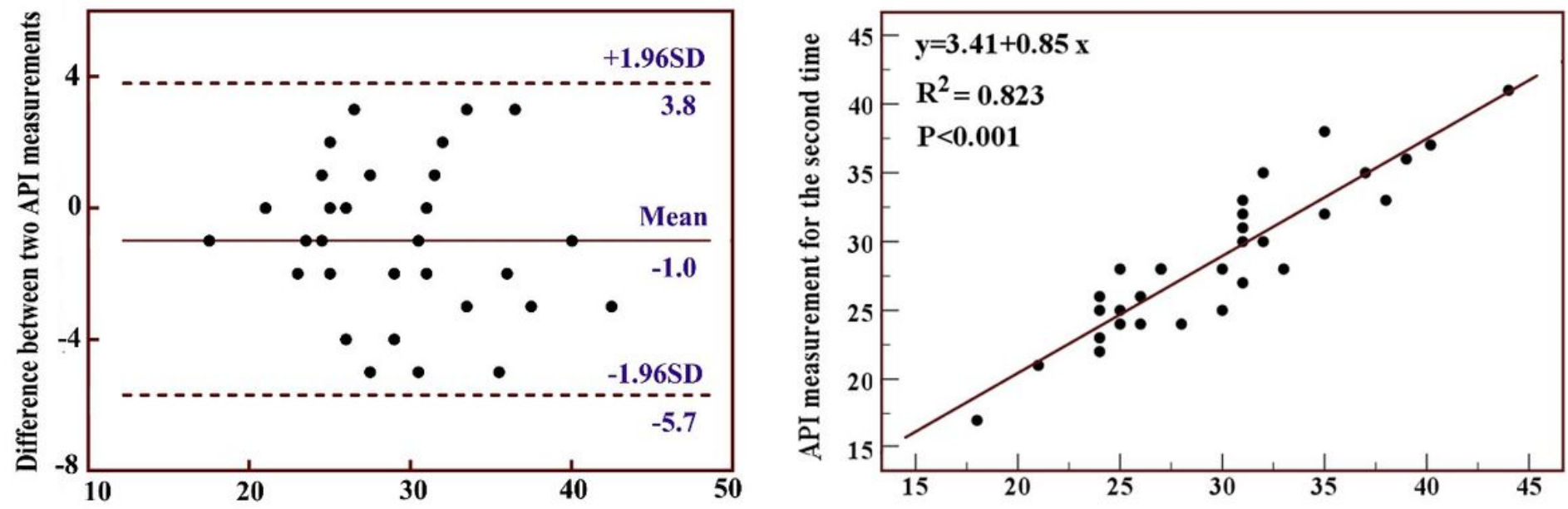

a

Mean of two API measurements

b

API measurement for the first time

Figure 2

Repeatability was analyzed by Bland-Altman Plots $(a)$ and linear correlation analysis $(b)(n=30)$. The results showed a consistent trend in the difference value and the mean value of API by repeated measurement. 

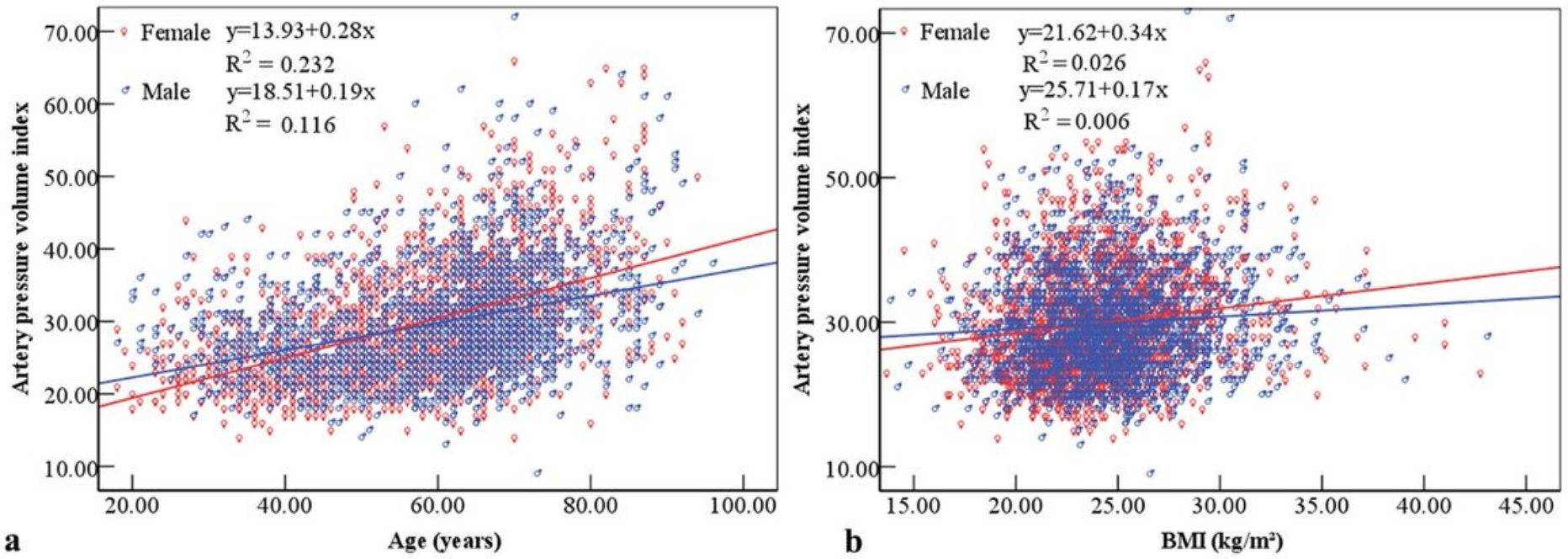

Figure 3

Correlation analysis of API with age and BMI in different genders. (a)Correlation analysis chart of API and age between male and female; (b)Correlation analysis chart of API and BMI between male and female.

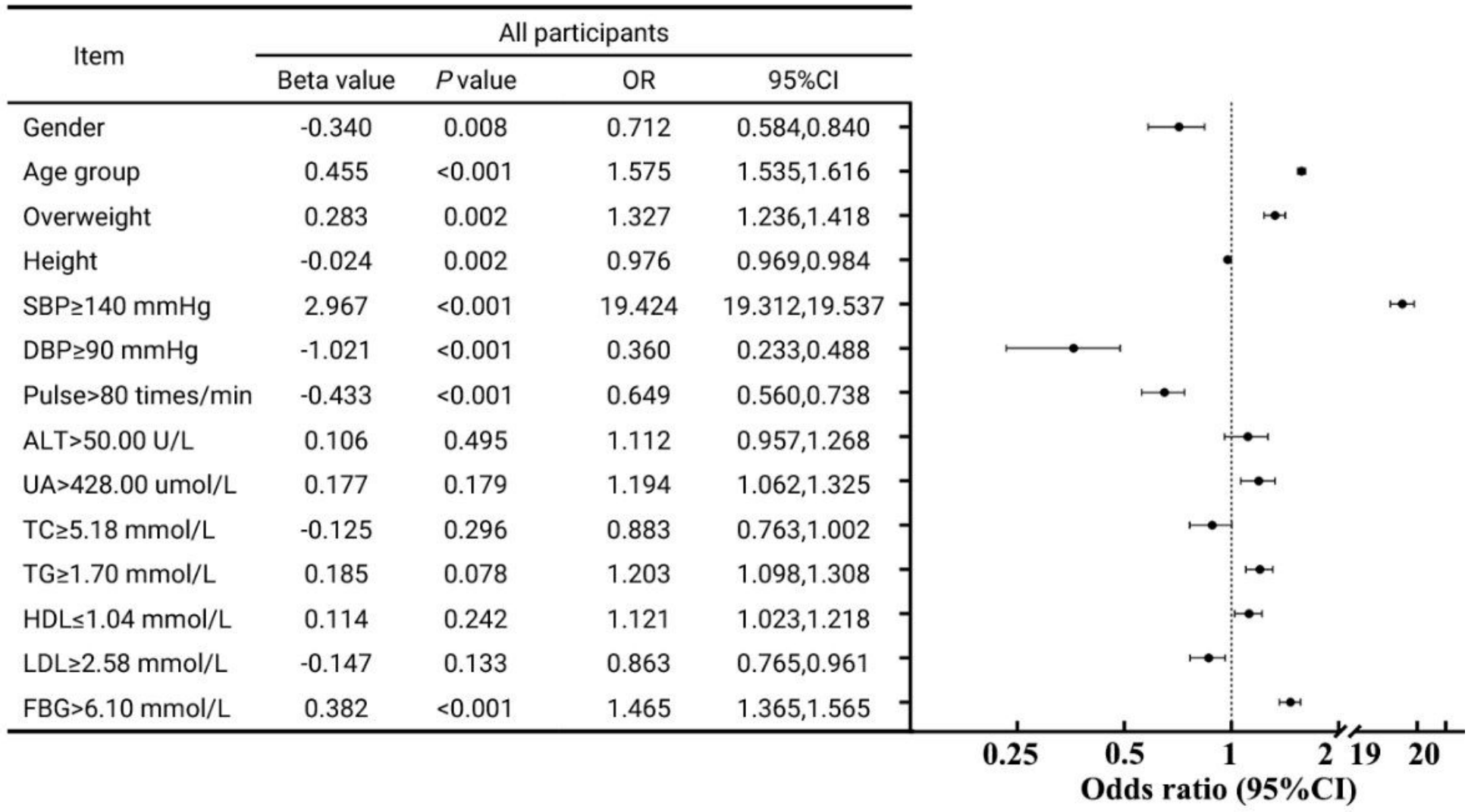

Figure 4

Forest plot shows that risk factors for increased API in all participants. BMI: Body mass index, SBP: Systolic blood pressure, DBP: Diastolic blood pressure, API: Arterial pressure volume index, ALT: Alanine aminotransferase, UA: Uric acid, TC: Cholesterol, TG: Triglycerides, HDL: High-density lipoprotein, LDL: lowdensity lipoprotein, FBG: Fasting blood glucose 